\title{
One year of Lung Ultrasound in children with SarsCoV2 infection admitted to a tertiary referral children's hospital: a retrospective, single-center study, during 2020-2021 period.
}

Anna Maria Musolino ${ }^{1}$, Valentina Ferro ${ }^{2}$, Maria Chiara Supino $^{1}$, Elena Boccuzzi ${ }^{2}$, Simona Scateni $^{1}$, Serena Sinibaldi ${ }^{2}$, Laura Cursi ${ }^{1}$, Paolo Maria Schingo ${ }^{3}$, Antonino Reale ${ }^{1}$, Andrea Campana $^{2}$, Massimiliano Raponi ${ }^{3}$, Alberto Villani ${ }^{1}$, and Paolo Toma ${ }^{1}$

${ }^{1}$ Ospedale Pediatrico Bambino Gesu

${ }^{2}$ Bambino Gesu Pediatric Hospital

${ }^{3}$ Ospedale Pediatrico Bambino Gesù

September 24, 2021

\begin{abstract}
Background: The aim of this study was to analyze the lung ultrasound (LUS) patterns in combination with clinical-laboratory profiles of children hospitalized for COVID-19 infection in relation to temporal trend of the Italian epidemic. Methods: This was a retrospective study conducted at a pediatric tertiary referral hospital from 15th March 2020 to 15 th March 2021 . We compared the characteristics of two periods of the pandemic outbreak, the first one in spring and summer (15th March-30th September 2020) and the second one in autumn and winter (1st October 2020-15th March 2021). Results: 28 patients (53.85\%) were in the first period, 24 patients (46.15\%) were in the second period. The disease severity score was significantly higher in the second period $(\mathrm{p}=0.02)$. We observed that the occurrence of the irregular pleural line was seen more frequently in the second period $(87.5 \%$ vs $60.71 \% ; \mathrm{p}=0.03)$. The B-lines were significantly more frequent in children in the second period $(87.5 \%$ vs $60 \% ; \mathrm{p}=0.03)$. The several but not-coalescent B-lines were significantly more frequent in the second period $(80 \%$ vs $41.7 \%$; $\mathrm{p}=0.05)$. The LUS score correlated significantly with the disease severity score with a strong relationship $(\mathrm{r}=0.51, \mathrm{p}=0.002)$. The second phase of the COVID-19 epidemic outbreak had a higher disease severity score than the first phase with a moderate correlation $(\mathrm{r}=0.42 ; \mathrm{p}=0.01)$. Conclusion: The LUS plays an important role in the evaluation of pulmonary involvement in children affected by COVID-19 during different periods of the pandemic in combination with clinical-laboratory findings.
\end{abstract}

\section{Hosted file}

Musolino \& Ferro et al. Manuscript.docx available at https://authorea.com/users/422715/ articles/538327-one-year-of-lung-ultrasound-in-children-with-sarscov2-infectionadmitted-to-a-tertiary-referral-children-s-hospital-a-retrospective-single-center-studyduring-2020-2021-period

\section{Hosted file}

Musolino \& Ferro, et al. Table 1.docx available at https://authorea.com/users/422715/ articles/538327-one-year-of-lung-ultrasound-in-children-with-sarscov2-infectionadmitted-to-a-tertiary-referral-children-s-hospital-a-retrospective-single-center-studyduring-2020-2021-period

\section{Hosted file}


Musolino \& Ferro, et al. Table 2.docx available at https://authorea.com/users/422715/ articles/538327-one-year-of-lung-ultrasound-in-children-with-sarscov2-infectionadmitted-to-a-tertiary-referral-children-s-hospital-a-retrospective-single-center-studyduring-2020-2021-period

\section{Hosted file}

Musolino \& Ferro, et al. Table 3.docx available at https://authorea.com/users/422715/ articles/538327-one-year-of-lung-ultrasound-in-children-with-sarscov2-infectionadmitted-to-a-tertiary-referral-children-s-hospital-a-retrospective-single-center-studyduring-2020-2021-period
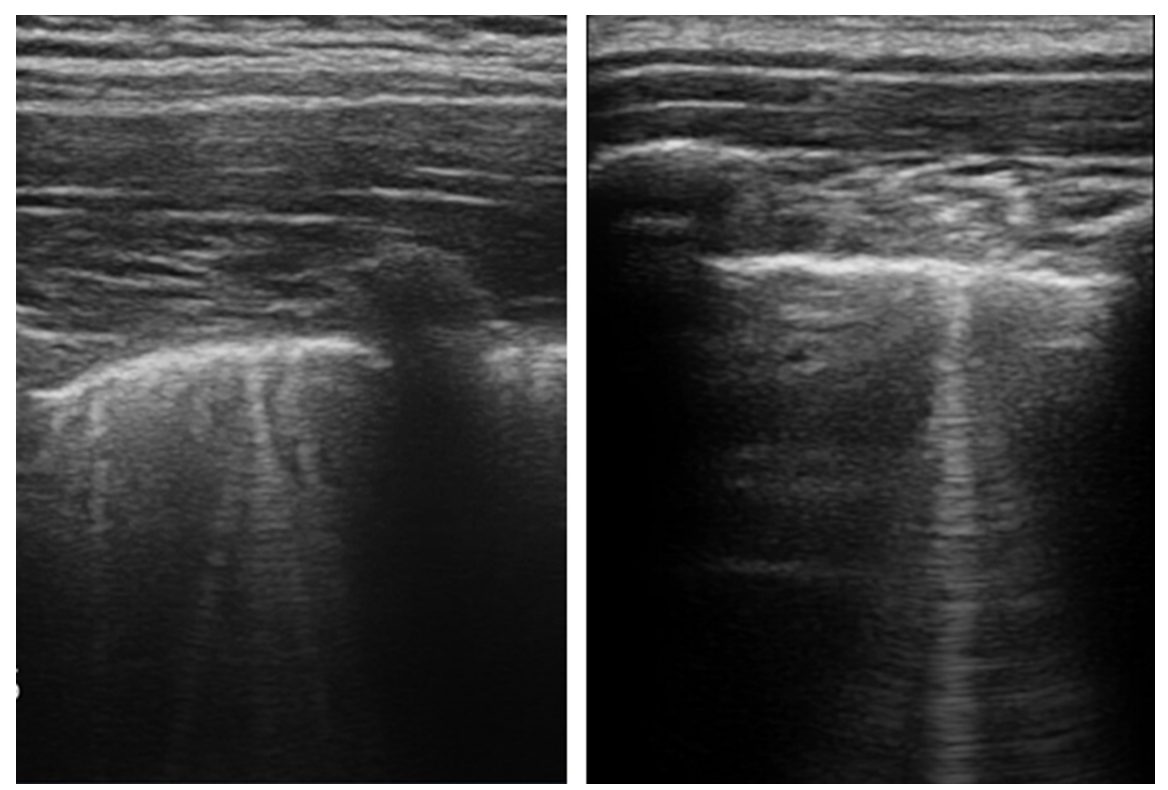


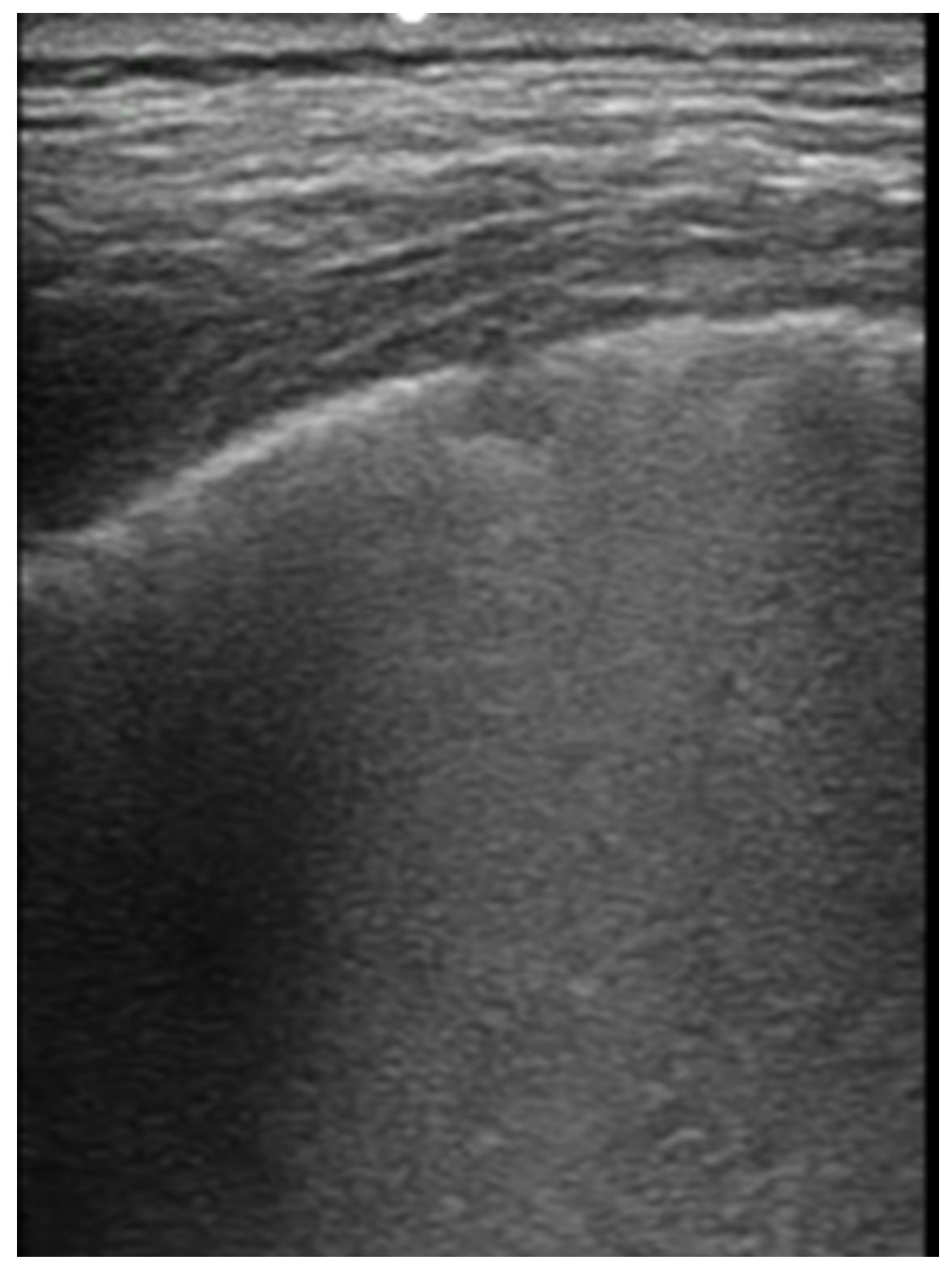

